\title{
Image texture analysis and colorimetry for the classification of uranium ore concentrate powders
}

\author{
$\underline{\text { Mara Marchetti }}{ }^{\star}$, Klaus Mayer, Maria Wallenius, Antonio Bulgheroni, Thierry Wiss, Klaus Lützenkirchen and \\ Lorenzo Fongaro \\ * European Commission, Joint Research Centre (JRC) \\ mara.marchetti@ec.europa.eu
}

\begin{abstract}
In the context of nuclear security, uranium ore concentrates (UOCs) play an important role: they are traded in large quantities and this makes their use "out of regulatory control" a possible scenario.

Once an incident of illicit trafficking o $\mathrm{f} n$ uclear $\mathrm{m}$ aterial is detected, an understanding of its origin and production process is required; this implies the necessity to use analytical techniques able to measure characteristic parameters (e.g. physical, chemical, isotopic characteristics of the nuclear materials) which are referred to, in the field of the nuclear forensics, a s signatures. The present study investigates the potential of image texture analysis (i.e. the angle measure technique), combined with the spectrophotometric determination of colours for the evaluation of the origin of several UOCs. The use of different multivariate statistical techniques allows the categorization of about 80 different samples into a few groups of UOCs powders, which makes this approach a promising method complementing the already established methods in nuclear forensics.
\end{abstract}

Keywords-Nuclear forensic science, Image texture analysis, spectrophotometry, PCA, SVM, AMT

\section{INTRODUCTION}

$\mathbf{T}$ HE illicit trafficking of nuclear and other radioactive materials represents a potential threat to the citizens, hence efforts are required in order to deter, detect, investigate and prosecute their illicit movement. In this context, nuclear forensics plays an important role. Since the early seizures of nuclear materials back in the 1990's an investigative approach has been gradually established for the identification of the origin and history of the material in a manner to support legal proceedings to the actors involved in the illicit trafficking [1]. This approach is the core of nuclear forensic science. The key in the tracing process is the identification of characteristic parameters or "signatures" which can relate a particular nuclear or other radioactive material to a production process, date and possibly to a production site. Examples of characteristic parameters are: chemical composition, isotopic abundances of $\mathrm{U}$ and $\mathrm{Pu}$, metallic impurities or physical morphologies.

Incidents involving nuclear materials out of "regulatory control" in the last decades have raised the necessity to include the early stages of the nuclear fuel cycle in the nuclear forensics investigations; in this scenario increasing interest has been attributed to the uranium ore concentrates (UOCs). They are produced after milling, leaching and precipitating uranium

Mara Marchetti is with the European Commission, Joint Research Centre (JRC), Ispra, Italy e-mail: mara.marchetti@ec.europa.eu

Klaus Mayer, Maria Wallenius, Antonio Bulgheroni, Thierry Wiss, Klaus Lützenkirchen and Lorenzo Fongaro are with the European Commission, Joint Research Centre (JRC), Karlsruhe, Germany

Manuscript received May 13, 2019 from the uranium ores. UOCs contain about $60-80 \%$ uranium in different chemical composition (e.g. ammonium diuranate, uranyl hydroxide, uranyl peroxide, or uranium oxide [2]) and are available in large quantities; this may lead to an increased risk of thefts for diversion purposes.

Different signatures have been identified in the field of nuclear forensics for UOCs which are related to their origin or production process, namely the isotope ratio of $\mathrm{U}$, in particular ${ }^{238} \mathrm{U} /{ }^{234} \mathrm{U}$ and ${ }^{235} \mathrm{U} /{ }^{234} \mathrm{U}$ [3]-[5], or that of $\mathrm{Pb}, \mathrm{Sr}$, $\mathrm{Nd}$ [6]-[9]), the measurement of trace level of ${ }^{232} \mathrm{Th}$ and ${ }^{228} \mathrm{Th}$ [10] or the impurities content [9], [11]. Recent works have highlighted the potential of discriminating different uranium ore concentrates on the basis of morphological information extracted by using image analysis. Keegan and co-workers have supported their conclusion on an unknown UOC sample thanks to a visual comparison performed via scanning electron microscopy (SEM) with the powder of the Mary Kathleen uranium mine [9]; Ho Mer Lin [12] and Fongaro et al. [13] have tested the potentiality of image texture analysis for the classification of 14 uranium ore concentrates characterised by different chemical compositions and production processes.

The present work aims to further investigate the approach used in [13]. Here, a batch of 79 commercial UOCs, produced in different facilities around the world (see section II), was used as training-samples; they were firstly classified on the basis of their colours by using diffuse-reflected spectrophotometry, cluster analysis and support vector machine (SVM) algorithm for classification. This allowed obtaining six different colour-groups of UOCs, hence performing a first differentiation among the powders. A further discrimination was then obtained by applying the Angle Measure Technique (AMT) algorithm within two colour-groups of samples; this last approach represents the preliminary phase of the image texture classification within each colour-group for the entire batch of 79 samples.

\section{MATERIALS AND METHODS}

\section{A. Uranium ore concentrate powders}

The 79 uranium commercial uranium ore concentrates investigated in the present experimental campaign are listed in Table I. 
TABLE I

UOC POWDERS MEASURED IN THE PRESENT EXPERIMENTAL CAMPAIGN.

\begin{tabular}{lll} 
England-Wheal Edward & 41 & Canada-North Span \\
USA-Kerr MgGee & 42 & USA-Utah \\
Spain-Jen & 43 & Australia-Ranger \\
Australia-Yeelirrie & 44 & Germany-Brunhilde \\
Namibia-Rossing & 45 & Germany-Ellweiler \\
Zambia-Mindola & 46 & Niger-Somair \\
USA-Cotter & 47 & Portugal \\
Gabon-EFI(Mouand) & 48 & USA-Lucky McGill \\
USA-Pathfinder & 49 & USA-Everest Black \\
Canada-Stanrock & 50 & Canada-Rio Algom \\
Holland-Delft & 51 & Canada-Rabbit Lake \\
Mozambique-Maruzi & 52 & USA-Everest Yellow \\
S.Africa-Palabora & 53 & Sweden-Ranstadt \\
Belgium-Belgian Congo & 54 & USA-El Mesquite \\
Brazil-Nuclebras & 55 & USA-Union Carbide \\
Spain-Enusa & 56 & Canada-Denison \\
Australia-Queensland & 57 & USA-Atlas \\
Germany-Wismut & 58 & Australia-Mary Kathleen \\
USA-Yankee Yellow & 59 & USA-United Uranium \\
Canada-Dyno & 60 & USA-South Dakota \\
Canada-Key Lake & 61 & Argentina \\
China-Hengyang & 62 & USA-Federal American Partners \\
USA-Petromic & 63 & USA-Dawn \\
Canada-Blind River & 64 & Canada-Milliken Lake \\
Canada-Gunnair & 65 & Australia-Rum Jungle \\
Yugoslavia-Spisak Black & 66 & Canada-El Dorado \\
Canada-Faraday & 67 & Canada-Ray Rock \\
Australia-Olympic Dam & 68 & USA-Chevron Hill \\
Yugoslavia-Spisak Yellow & 69 & S.Africa-Nufcor \\
USA-Mulberry & 70 & Russia-Techsnab \\
USA-Falls City & 71 & USA-United Nuclear \\
Canada-Madawaska & 72 & Yugoslavia-Rudnik \\
USA-Irigaray & 73 & Australia-South Alligator \\
USA-ESI & 74 & USA-Yankee Black \\
Canada-Macassa & 75 & USA-Sesquehanna \\
USA-Anaconda & 76 & Romania \\
USA-Shirley Basin & 77 & USA- White Mesa \\
USA-Mobil & 78 & USA-Homestake \\
Canada-ESI & 79 & Canada-Stanleigh \\
Australia-Radium Hill & & \\
& & \\
\hline
\end{tabular}

The set of UOCs consists of $\sim 30$ ammonium diuranate, six sodium diuranate, $\sim 10$ uranyl hydroxide, $\sim$ five uranyl peroxide, seven are triuranium octoxide and then two are of non-conventional chemical composition. Mixtures of ammonium diuranate-oxide or oxide-hydroxide complete the list.

For spectrophotometric investigations the samples were introduced in vials made of quartz $(75 \times 10 \mathrm{~mm})$ or in vials of borosilicate glass $(45 \times 14.7 \mathrm{~mm})$.

In the case of the SEM acquisitions, the powder was not coated due to the necessity of reusing it for future analyses. It was inserted inside a disc made of graphite and gently pressed with a weight of $1 \mathrm{~g}$. In general, three different repetitions were used for each UOC powder (to consider the variability introduced with the preparation); this number was reduced to two when the available amount of sample was insufficient.

\section{B. Spectrophotometry}

The colour of the samples was measured by means of a portable Konika Minolta CM-700d sphere-type spectrophotometer, which is characterized by a silicon photodiode array detector and an integrating sphere having a diameter of 40 $\mathrm{mm}$. This spectrophotometer uses a xenon lamp equipped with a UV cut filter and operates in the visible range of the electromagnetic spectrum $(\sim 400-700 \mathrm{~nm})$.

The light reflected by the sample is collected in the integrating sphere and then is normalized to the zero reflection condition and to a pure white standard (100\% reflection). The reflectance values as a function of the wavelength were collected, together with the "tristimulus values" in terms of $L^{*}, a^{*}, b^{*}$ in the $\mathrm{L}^{*} \mathrm{a}^{*} \mathrm{~b}$ colour space, where [14]:

$$
\begin{gathered}
L^{*}=116 f\left(\frac{Y}{Y_{n}}\right)-16 \\
a^{*}=500\left(f\left(\frac{X}{X_{n}}\right)-f\left(\frac{Y}{Y_{n}}\right)\right) \\
b^{*}=200\left(f\left(\frac{Y}{Y_{n}}\right)-f\left(\frac{Z}{Z_{n}}\right)\right)
\end{gathered}
$$

$\mathrm{X}, \mathrm{Y}, \mathrm{Z}$ are the tristimulus values of the considered object; $X_{n}, Y_{n}$ and $Z_{n}$ are those of the perfect reflecting standard.

\section{Scanning electron microscopy image acquisition and angle measure technique (AMT)}

SEM images of the UOC powders: $10,11,33,38,51,52$, 54,63 , were acquired using a FIB/SEM FEI Versa 3D in lowvacuum mode (pressure $=10 \mathrm{~Pa}$ ) equipped with a concentric backscattered detector for backscattered electrons.

In order to reduce the electrostatic charging phenomenon, due to the interaction between the electrons and the UOC powders, a voltage of $5 \mathrm{kV}$ was applied to the electron beam and the images were acquired using a maximum magnification of 500 $\mathrm{x}$, with a dimension of $3072 \times 2048$ pixels.

The acquisition was performed in integration mode (16 frames to obtain an image), with a dwell time of 300 ns. For each UOC powder 15 independent images per magnification were acquired and stacked, then mean-centred with a plugin for ImageJ $1.51 \mathrm{j} 8$ [15], in a manner to obtain a more uniform contrast prior to the analysis [13].

The texture of the images, which is strictly linked to the physical surface texture, is usually defined as the relationship of the intensity values, frequencies and spatial distribution among all the pixels in the image [16]. Different measures of the image texture are possible, one of these is the AMT. The angle measure technique was introduced by Andrle [17] to characterize the complexity of geomeorphic lines. In image texture analysis, AMT operates in the following manner: 


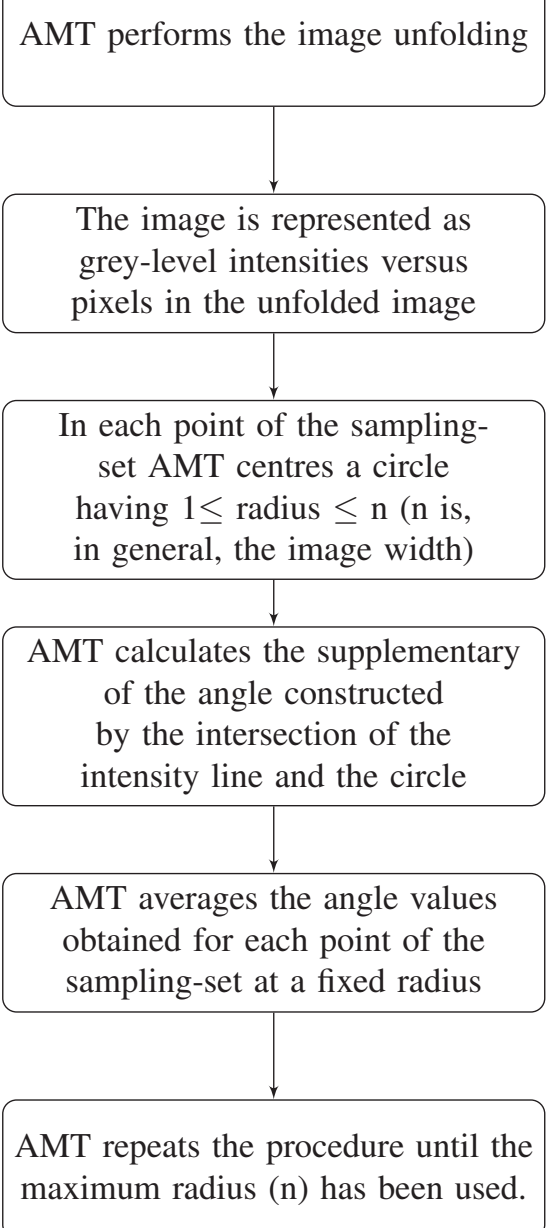

The reader can find detailed explanation of the AMT algorithm in [13], [17]-[19].

D. Multivariate statystical analysis: cluster analysis, principal components analysis (PCA) and support vector machine (SVM)

In the present work reflectance spectra and $L^{*}, a^{*}, b^{*}$ values were analysed by means of cluster analysis and support vector machine algorithms. Principal components analysis was applied to the AMT spectra of two groups of samples. For multivariate statistical analysis we used a PLS Toolbox version 8.6.1 (Eigenvectors Research, Inc., USA) for Matlab 2017a (The Matworks Inc., Natick, MA, USA).

1) Cluster analysis: The aim of the cluster analysis is to group a large number of objects on the basis of an appropriate criterion applied to a matrix of multivariate measurements of these objects. The clustering must be performed in a manner to maximize the differences among the groups while minimizing those within them [20]. Different algorithms are available; here, the hierarchical Ward's method was used. This method joins two clusters that minimise the sum of the square errors [21], hence the increase of variation inside the groups.

2) Principal components analysis: PCA is a technique that allows extracting information from the covariance or correlation matrix in a manner that a group of variables can be reduced in dimensionality. PCA performs linear combinations of the observed variables that represent the so-called "principal components" and are able to explain most of the variance in the original variables. The coefficients of the linear combination are the loadings corresponding to each extracted principal component. [22]. PCA is a data reduction technique that is widely used in the explorative analysis.

3) Support vector machine: Support vector machine is a kernel-based algorithm for classification and regression analysis. In classification, SVM uses a function generated by learning from the original data which finds the hyperplane maximizing the distance among the available classes of data.

\section{RESULTS}

\section{A. Colour-groups}

The 39 variables, corresponding to the reflectance values in the range $360-740 \mathrm{~nm}$, were coupled with the $L^{*}, a^{*}, b^{*}$ values for each powder in Table I and statistically treated. Fig. 1 shows the clustering representation obtained by applying Ward's method on the data pre-processed with the autoscale function. It is possible to choose different combinations, however, that with 6 colour-groups was chosen.

Once performed the colour-classes selection, these were renamed in: Whyello (white-yellow), Yellow, Dyello (Darkyellow), Orange, Brown and Black.

It is worthwhile to notice that peroxides belong mostly to the first g roup, a mmonium d iuranate, s odium d iuranate and hydroxides to Yellow, Dyello and Orange (differences in the yellow nuances are most likely linked to the production processes). Mixed compounds are in the Brown class whilst the Black group contains oxides. This result highlights the capability of the statistical analysis in identifying links between the powders production process and their colours.

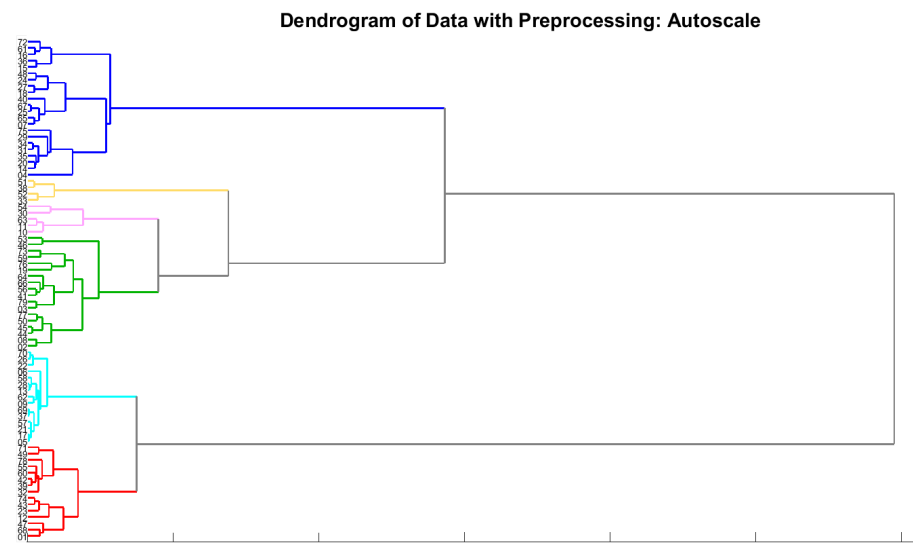

Fig. 1. Hierarchical cluster analysis of the entire samples collection. Different clusters are possible by selecting the position on the dendogram. In this work the 6 different colour-groups were chosen.

The above-mentioned classes were used as category variables for the SVM colour-based classification, hence each sample was renamed according to the corresponding class. To achieve the classification, SVM implemented with LIBSVM library and the Radial Basic Function Kernel were employed; data were then pre-processed by means of the autoscale function whilst a maximum cost of 50 was selected (50 was 
chosen among the lower costs having the best performance). Table II lists the sensitivities and the specificities obtained with the present model which has a Root Mean Square Error Cross Validation (RMSECV) of 0.420969. The model is able to attribute each sample in Table I in the correct class.

Figures 2 and 3 provide an example of the results obtained: all the samples belonging to the Whyello and Yellow categories are correctly classified. These samples were successively used for the preliminary image texture analysis and sub-classification. The model was validated by using a set of additional measures of 25 UOC powders, which represents the validation dataset. The model attributes 24/25 samples to the correct class, while misclassifies one Orange sample as Yellow. This result appears satisfactory, especially considering the low RMSECV obtained.

TABLE II

SENSitivities AND SPECIFICITIES IN CALIBRATION AND CROSS-VALIDATION FOR THE SVM CLASSIFICATION PERFORMED ON THE 6 COLOUR-CLASSES OF SAMPLES. THE ROOT MEAN SQUARED ERROR IN CROSS-VALIDATION (RMSECV): 0.420969

$\begin{array}{lllllll}\text { Sensitivity (Cal) } & 1.000 & 1.000 & 1.000 & 1.000 & 1.000 & 1.000 \\ \text { Specificity (Cal) } & 1.000 & 1.000 & 1.000 & 1.000 & 1.000 & 1.000 \\ \text { Sensitivity (CV): } & 0.933 & 1.000 & 0.955 & 1.000 & 0.800 & 1.000 \\ \text { Specificity (CV): } & 1.000 & 0.967 & 0.982 & 1.000 & 1.000 & 1.000 \\ \text { Class. Err (Cal): } & 0 & 0 & 0 & 0 & 0 & 0 \\ \text { Class. Err (CV): } & 0.0333 & 0.0164 & 0.0315 & 0 & 0.1 & 0\end{array}$

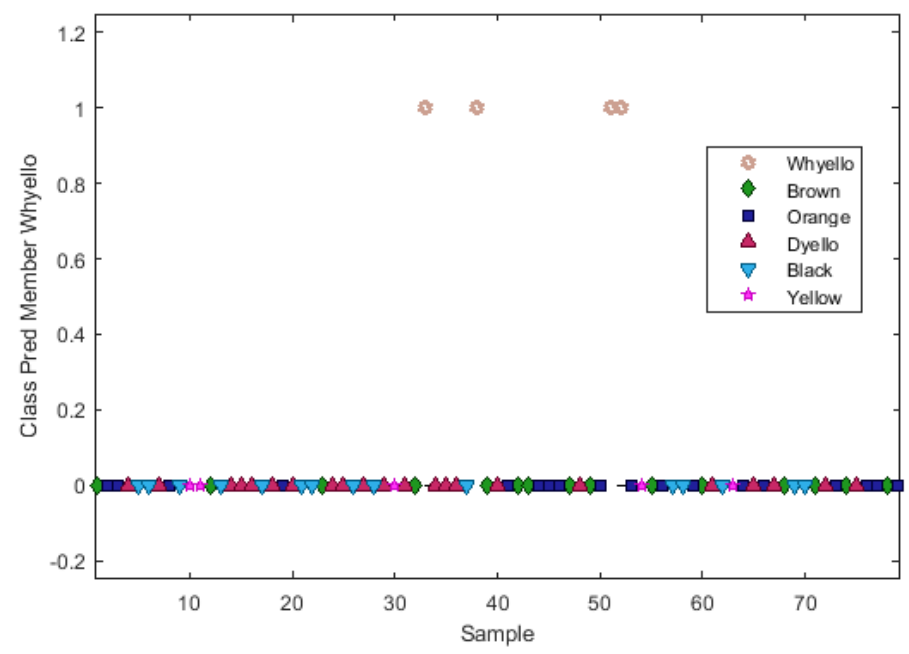

Fig. 2. Classification results for the samples pre-classified as Whyello. The classification prediction membership is measured either by a 0 (nonmembership) or by a 1 (membership). These values are assigned on the basis of the highest probability of belonging to a particular group. Specifically, each sample in the Whyello class is correctly assigned.

\section{B. Subgroups exploration}

The determination of the colour-groups enabled us to perform first discrimination among the UOC powders available in the present study. To enhance the differentiation capability, the samples within a specific colour-group must be further separated by applying a technique capable to tackle possible

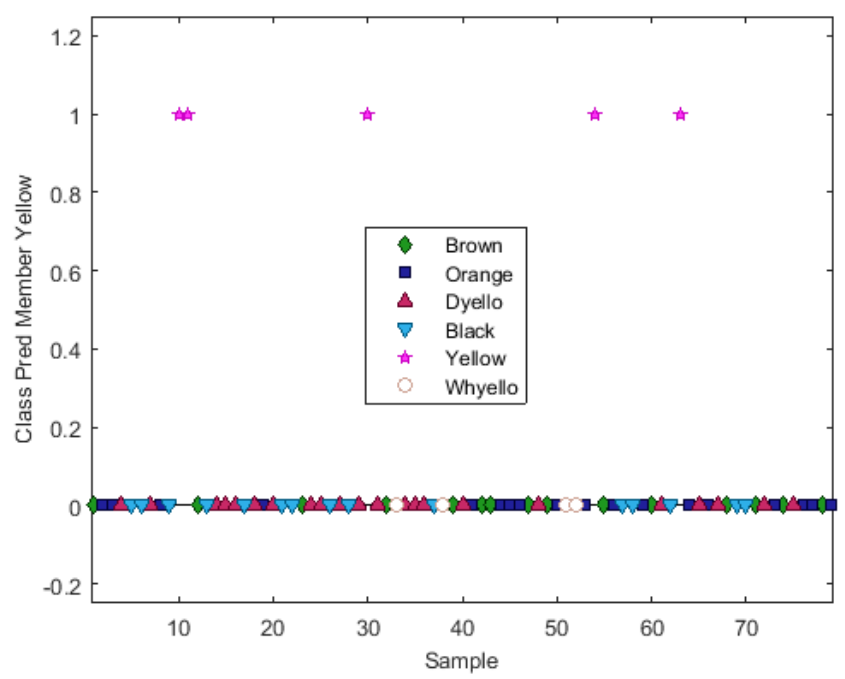

Fig. 3. Classification $\mathrm{r}$ esults $\mathrm{f}$ or $\mathrm{t}$ he $\mathrm{s}$ amples $\mathrm{p}$ re-classified as Yellow. The classification $\mathrm{p}$ rediction $\mathrm{m}$ embership i s m easured $\mathrm{e}$ ither b y a 0 (nonmembership) or by a 1 (membership). These values are assigned on the basis of the highest probability of belonging to a particular group. Specifically, each sample belonging to the Yellow class is correctly assigned.

additional differences.

Most of the samples in one colour-group have the same chemical composition, however, the production route causes differences in the morphology of the powders, in particular in the powder's texture (i.e. particle size, size distribution, homogeneity and shape), which is reflected on the texture of the acquired images.

The images at $500 \mathrm{x}$ of the samples in subsection II-C and belonging to the Whyello and Yellow groups were selected. In general acquisition of the images of peroxides was more difficult. T he i mages of $51,38,52$ a nd 33 (Whyello) were stacked together and pre-processed as already explained in subsection II-C; the same operation was performed on 10, 11, 54 and 63 (Yellow). The images were then reduced in dimension (as suggested by Kucheryavski and co-workers) [23] to $600 \times 400$ and a sampling of $2 \%$ was chosen for shorter calculation time. The mean angle values of the five replicates obtained for each sample repetition were averaged which provided three mean angle distributions for each facility-class. Fig. 4 shows the averaged mean angle spectral data for the Yellow category samples, together with their textural images. AMT spectra are in general complex and interpretation is not straightforward, however, high mean angle (MA) values can be interpreted as a high variation in the image texture complexity, while low values are more related to a lower variation [18]: in the Yellow category the highest complexity is displayed by the specimen number 10 (Canada Stanrock), the lowest by number 63 (USA Dawn).

These spectra were successively analysed using PCA (autoscale preprocessing and leave-one-out cross-validation): Figures 5 and 6 show respectively the score-plots of the Whyello and Yellow samples. In both cases two components were chosen: for Yellow UOCs this choice explains $99.35 \%$ of the variance $(\mathrm{PC} 1=94.6 \%$; $\mathrm{PC} 2=4.7 \%)$; for Whyello UOCs the 
explained variance is $86.19 \%(\mathrm{PC} 1=48.6 \%$; $\mathrm{PC} 2=37.59 \%)$. In both cases outliers in terms of Q-residuals and Hotelling number $\mathrm{T}^{2}$ [24] were absent, only one average value of the sample 51 was borderline in terms of Q-residuals, but this value was included in the exploratory analysis. In both Figures 5 and 6 it is possible to identify samples clusters within the same colour-group: in the Whyello, overlapping between Canada Rabbit Lake (51) - USA Irigaray (33) and USA Mobil (38) - USA Everest Yellow (52) are clearly visible; in the Yellow group the facilities-classes are separated mostly along the PC1, where it is possible to recognize the "trend" observed in Fig. 4: USA Dawn (63) has the largest negative score along PC1 (lowest mean angle values), whilst Canada Stanrock the larger positive score along the same PC (higher mean angle values). The overlapping among clusters observed in the Whyello analysis is most probably caused by the difficult image acquisitions of the UOC powders containing peroxides, this would suggest that actions must be taken to limit the charging phenomena such as coating the powder with a conducting material.

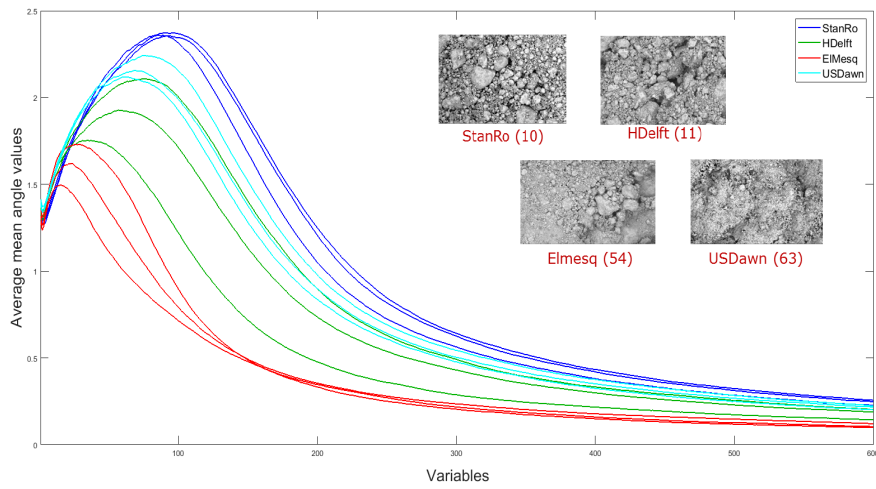

Fig. 4. Average mean angle spectra for the UOCs belonging to the Yellow group together with SEM images of the specimens displaying their texture

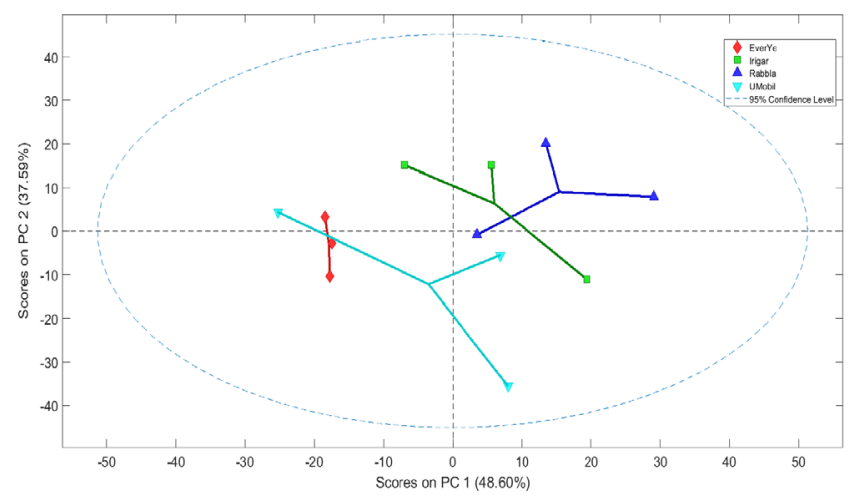

Fig. 5. PCA of the average mean angle spectra obtained with the UOC powders in the Whyello group

\section{CONCLUSION}

The present study aims to investigate a new methodology in nuclear forensic science, capable to provide hints on the

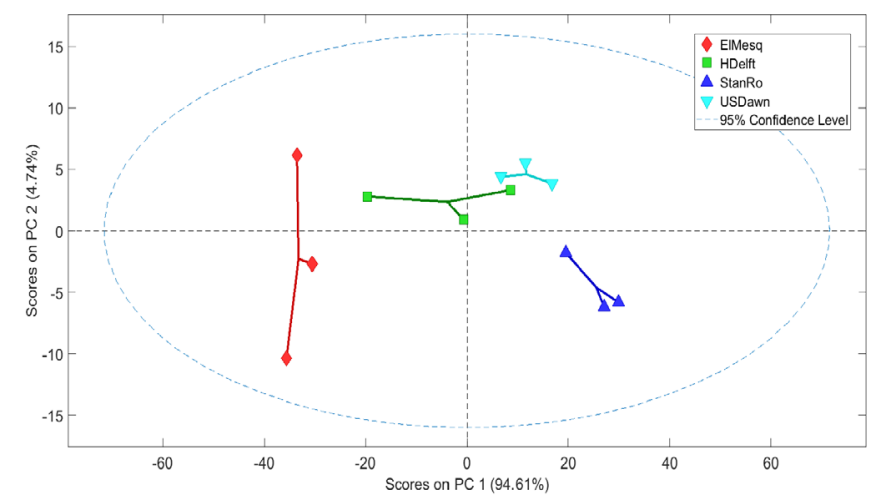

Fig. 6. PCA of the average mean angle spectra obtained with the UOC powders in the Yellow group

origin of uranium ore concentrates in a fast and simple manner. The route explores the potentiality of multivariate statistical analysis applied to techniques that could highlight differences among the powders which are based on the chemical composition and which were obtained through the same generic production process. The first part of the study provides a model based on the combination of spectrophotometry and support vector machine algorithm which is capable to restrict the field of investigation among a few facilities only on the basis of the colour of the sample. The model was validated and, then, finalised. The second part of the study is a preliminary attempt to distinguish among samples belonging to the same colourgroup: to achieve this goal AMT image texture analysis was used and its potentiality, as signature in nuclear forensics, was investigated by using the Principal Components Analysis. In this last case results are promising, a first discrimination among the determined facilities-classes, thus the different production processes, appears possible. However, different algorithms or combination of other image texture analyses will be further investigated in order to obtain a model which can provide reliable nuclear forensics findings.

\section{ACKNOWLEDGMENT}

The authors convey their gratefulness to Alessandro Benedetti and Markus Ernstberger for the assistance received when using the FIB/SEM, Adrian Nicholl and Martin Vargas Zuniga for their openness toward helping out when needed. The present work has been financially supported by the European Commission in the frame of the Exploratory Research programmes.

The authors thank the Scientific Development Unit of the Joint Research Centre Ispra, for supporting the activities of the IDENTICLASS project.

\section{REFERENCES}

[1] IAEA, "Nuclear forensics support," International Atomic Energy Agency, Tech. Rep., 2006.

[2] M. J. Kristo, A. M. Gaffney, N. Marks, K. Knight, W. S. Cassata, and I. D. Hutcheon, "Nuclear forensic science: Analysis of nuclear material out of regulatory control," Annual Review of Earth and Planetary Sciences, vol. 44, no. 1, pp. 555-579, 2016. 
[3] E. Keegan, S. Richter, I. Kelly, H. Wong, P. Gadd, H. Kuehn, and A. Alonso-Munoz, "The provenance of Australian uranium ore concentrates by elemental and isotopic analysis," Applied Geochemistry, vol. 23, no. 4, pp. $765-777,2008$.

[4] G. A. Brennecka, L. E. Borg, I. D. Hutcheon, M. A. Sharp, and A. D. Anbar, "Natural variations in uranium isotope ratios of uranium ore concentrates: Understanding the 238U/235U fractionation mechanism," Earth and Planetary Science Letters, vol. 291, no. 1, pp. 228 - 233, 2010.

[5] T. L. Spano, A. Simonetti, E. Balboni, C. Dorais, and P. C. Burns, "Trace element and $\mathrm{U}$ isotope analysis of uraninite and ore concentrate: Applications for nuclear forensic investigations," Applied Geochemistry, vol. 84 , pp. $277-285,2017$.

[6] Z. Varga, M. Wallenius, K. Mayer, E. Keegan, and S. Millet, "Application of lead and strontium isotope ratio measurements for the origin assessment of uranium ore concentrates," Analytical Chemistry, vol. 81, no. 20, pp. 8327-8334, 2009.

[7] J. Švedkauskaite LeGore, K. Mayer, S. Millet, A. Nicholl, G. Rasmussen, and D. Baltrunas, "Investigation of the isotopic composition of lead and of trace elements concentrations in natural uranium materials as a signature in nuclear forensics," Radiochimica Acta, vol. 95, no. 10, pp. 601-605, 2007.

[8] J. Krajkó, Z. Varga, E. Yalcintas, M. Wallenius, and K. Mayer, "Application of neodymium isotope ratio measurements for the origin assessment of uranium ore concentrates," Talanta, vol. 129, pp. 499 - 504, 2014.

[9] "Nuclear forensic analysis of an unknown uranium ore concentrate sample seized in a criminal investigation in Australia," Forensic Science International, vol. 240, pp. 111 - 121, 2014.

[10] Z. Varga, M. Wallenius, K. Mayer, and E. Hrnecek, "Alternative method for the production date determination of impure uranium ore concentrate samples," Journal of Radioanalytical and Nuclear Chemistry, vol. 290, no. 2, pp. 485-492, Nov 2011.

[11] A. K. Kennedy, D. A. Bostick, C. R. Hexel, R. R. Smith, and J. M. Giaquinto, "Non-volatile organic analysis of uranium ore concentrates," Journal of Radioanalytical and Nuclear Chemistry, vol. 296, no. 2, pp. 817-821, May 2013.

[12] D. M. L. Ho, "Study on the applicability of structural and morphological parameters on selected uranium compounds for nuclear forensic purposes," Ph.D. dissertation, 2015.

[13] L. Fongaro, D. M. L. Ho, K. Kvaal, K. Mayer, and V. V. Rondinella, "Application of the angle measure technique as image texture analysis method for the identification of uranium ore concentrate samples: New perspective in nuclear forensics," Talanta, vol. 152, pp. 463 - 474, 2016.

[14] J. Schanda, Colorimetry: understanding the CIE system. John Wiley \& Sons, 2007.

[15] C. A. Schneider, W. S. Rasband, and K. W. Eliceiri, "Nih image to imagej: 25 years of image analysis," Nature methods, vol. 9, no. 7, p. 671,2012

[16] J. C. Russ, The image processing handbook, 3rd ed. CRC press, 1999, ch. 4 .

[17] R. Andrle, "The angle measure technique: A new method for characterizing the complexity of geomorphic lines," Mathematical Geology, vol. 26, no. 1, pp. 83-97, Jan 1994.

[18] J. Huang and K. H. Esbensen, "Applications of Angle Measure Technique (AMT) in image analysis: Part I. a new methodology for in situ powder characterization," Chemometrics and Intelligent Laboratory Systems, vol. 54, no. 1, pp. 1 - 19, 2000. [Online]. Available: http://www.sciencedirect.com/science/article/pii/S0169743900001003

[19] K. H. Esbensen, K. H. Hjelmen, and K. Kvaal, "The AMT approach in chemometrics-first forays," Journal of Chemometrics, vol. 10, no. 5-6, pp. 569-590, 1996.

[20] W. Härdle and L. Simar, Applied multivariate statistical analysis. Springer, 2007, vol. 22007.

[21] T. Strauss and M. J. von Maltitz, "Generalising wards method for use with manhattan distances," PloS one, vol. 12, no. 1, p. e0168288, 2017.

[22] D. J. Denis, Applied univariate, bivariate, and multivariate statistics. John Wiley \& Sons, 2015

[23] S. V. Kucheryavski, K. Kvaal, M. Halstensen, P. P. Mortensen, C. K. Dahl, P. Minkkinen, and K. H. Esbensen, "Optimal corrections for digitization and quantification effects in angle measure technique AMT texture analysis," Journal of Chemometrics: A Journal of the Chemometrics Society, vol. 22, no. 11-12, pp. 722-737, 2008.

[24] K. A. Bakeev, Process analytical technology: spectroscopic tools and implementation strategies for the chemical and pharmaceutical industries. John Wiley \& Sons, 2010. 